C. Tilikete, MD, PhD

L. Jasse

D. Pelisson, PhD

S. Vukusic, MD, PhD

F. Durand-Dubief, MD

C. Urquizar

A. Vighetto, MD

Address correspondence and reprint requests to Dr. Caroline Tilikete, INSERM U1028, Lyon Neuroscience Research Center, IMPACT team, Lyon,

F-69000, France

caroline.tilikete@inserm.fr

Supplemental data at www.neurology.org

\section{Acquired pendular nystagmus in multiple sclerosis and oculopalatal tremor}

\section{ABSTRACT}

Objective: Acquired pendular nystagmus occurs mainly in multiple sclerosis (MS) and focal brainstem lesions. In the later case, it is part of the syndrome of oculopalatal tremor. Even though pathophysiology of acquired pendular nystagmus has been clearly characterized experimentally in both etiologies, there is a persisting ambiguity in clinical literature, which leads one to consider both clinical conditions as a common entity. The objective of our work was to compare in a prospective study clinical features, eye movement recording, and functional consequences of acquired pendular nystagmus in 14 patients with oculopalatal tremor and 20 patients with MS.

Methods: Besides complete neurologic evaluation, evaluation of visual function, 3-dimensional eye movement recording, and functional scores of the Visual Function Questionnaire were recorded.

Results: One patient with oculopalatal tremor and 15 patients with MS disclosed signs of optic neuropathy. The nystagmus in the oculopalatal group showed significant larger mean amplitude (8 deg vs $1 \mathrm{deg}$ ), higher mean peak velocity (16 deg/s vs $6 \mathrm{deg} / \mathrm{s})$, lower mean frequency $(1-3 \mathrm{~Hz}$ vs 4-6 Hz), and larger asymmetry and irregularity of ocular oscillations compared to the MS group. The vision-specific health-related quality of life was more deteriorated in the oculopalatal tremor group than in the MS group.

Conclusions: This study emphasizes the need to consider acquired pendular nystagmus in MS and oculopalatal tremor as 2 different clinical entities. This is of particular importance regarding the future evaluation of potential specific effects of pharmacologic agents. Neurology ${ }^{\circledR} 2011 ; 76: 1650-1657$

\section{GLOSSARY}

APN = acquired pendular nystagmus; ION = inferior olivary nucleus; $\mathbf{M S}=$ multiple sclerosis; OPT = oculopalatal tremor; VFQ-25 = 25-item National Eye Institute Visual Function Questionnaire.

Pendular nystagmus corresponds to an enduring to and fro eye oscillation without resetting quick phases. The most common causes of acquired pendular nystagmus (APN) are multiple sclerosis (MS) and focal brainstem lesions. In the later case, APN arises as a feature of the oculopalatal tremor (OPT) syndrome. OPT develops weeks, months, or even years after a single brainstem or cerebellar lesion, ${ }^{1-3}$ in most cases a hemorrhagic stroke. It results in synchronized low-frequency tremor of the eyes and palate or other orofacial motor territories and is associated with an hypertrophic degeneration of the inferior olivary nucleus (ION), ${ }^{2}$ leading to T2 hypersignal on MRI. ${ }^{1}$ This condition is triggered by interruption of the GuillainMollaret triangle. ${ }^{2,4}$

Even though both etiology and clinical aspects appear different in APN associated with MS or OPT, ${ }^{5}$ many neurologists are not familiar with the distinct pathogenesis and characteristics of nystagmus in these 2 syndromes. Furthermore, some pharmacologic studies and nystagmus treatment reviews did not differentiate their results according to the underlying etiology. ${ }^{6-10}$

In this study, we aimed to compare clinical features, eye movement recordings, and functional consequences of APN in patients with MS or OPT. The main objective was to empha-

From the INSERM U1028, Lyon Neuroscience Research Center, IMPACT team (C.T., L.J., D.P., C.U., A.V.), Lyon; Université Claude Bernard Lyon I (C.T., S.V., A.V.), Lyon; Hospices Civils de Lyon, Unité de Neuro-Ophtalmologie and Service de Neurologie D (C.T., A.V.), and Hospices Civils de Lyon, Service de Neurologie A (S.V., F.D.-D.), Hôpital Neurologique, Bron, France.

Study funding: Supported by "Projet de Recherche Clinique des Hospices Civils de Lyon" grant no. HCL/P/2006.432/25.

Disclosure: Author disclosures are provided at the end of the article. 
size the different clinical aspects associated with these 2 etiologies and the need to consider APN in MS or OPT as 2 different entities with different underlying mechanisms. This is particularly important for evaluating potential specific effects of pharmacologic agents.

METHODS Patients. Starting in 2007, we prospectively included 14 patients with APN in the context of OPT syndrome and 20 patients with APN in the context of MS (table e-1 on the Neurology ${ }^{\circledR}$ Web site at www.neurology.org).

OPT group. This group consisted of 10 men and 4 women with a mean age of 50 . As seen from the MRI data (figure 1A), all patients had a focal brainstem lesion at the pontine level. The visual impairment and accompanying ION hypersignal (figure 1B) developed 1 month to 10 years after the initial neurologic event. The examination disclosed nystagmus of pendular form, irregular in amplitude, of low and irregular frequency, predominantly in the vertical direction, which was clinically asymmetric between the 2 eyes in all cases.

MS group. This group consisted of 11 men and 9 women with a mean age of 44 . All patients were tested at least 3 months after an acute phase. The median EDSS score was 6 (range 1-8). The examination disclosed pendular nystagmus of regular quasi-sinusoidal form, high frequency, mainly in the horizontal direction, that was clinically symmetric in 17 patients, and asymmetric in 3 patients. MRIs in 10 out of the 20 patients showed multiple areas of patchy hypersignal at the level of the pontine tegmentum (figure 1C) without ION hypersignal (figure 1D).

Standard protocol approval, registrations, and patient consent. Approval was received from the National French ethical committee on human experimentation, in agreement with French law (March 4, 2002) and the Declaration of Helsinki (no. 2007-008B). Written informed consent was obtained from all patients participating in the study.

Evaluation of visual function. All patients underwent a thorough ophthalmic examination including fundi and bestcorrected visual acuity measurement. Monocular visual acuity was determined with the Monoyer scale for far vision and the Parinaud scale for near vision. The results were converted in $\log$ MAR. In the MS group, the presence of underlying chronic optic neuropathy was tested by evaluating automatic visual field and static contrast sensitivity (Metrovision, Pérenchies, France) and the Farnsworth-Munsell D-15 Hue test was used to test color vision. The diagnosis of optic neuropathy was established according to the criteria detailed in appendix e-1.

Eye movements. Eye movement recordings. A quantitative recording of eye movements for each eye in the 3 axis dimensions was performed in all 34 patients using infrared videooculography ( $25 \mathrm{~Hz}$ frequency; Synapsys ${ }^{\circledR}$, Marseille, France). Details of the eye movement software analysis and calibration are given in appendix e-2.

Eye movement analysis. Based on the trajectories of each eye projected in the 3 planes, the following values were extracted: the dominant plane $(\mathrm{H}, \mathrm{V}$, or $\mathrm{T})$ was the plane in which the largest amplitude of eye oscillation was measured; the mean amplitude and the mean peak velocity were calculated on 20 consecutive cycles of nystagmus in the dominant plane; the frequency of pendular nystagmus was manually calculated over a 30-second period (for the purpose of analyzing more precisely the frequency of nystagmus, we also performed a fast Fourier transform of 2D eye position data [200 Hz frequency recording] in 15 patients with MS and 5 patients with OPT); the symmetry index was defined by the absolute value of the following equation: $\left(100 \times\left[A_{R E}-A_{L E}\right] /\left[A_{R E}+A_{L E}\right]\right)$, where $A_{R E}$ and $A_{L E}$ are the mean amplitude of the right and left eye in the dominant plane. ${ }^{11}$

VFQ-25. To examine vision-specific health-related quality of life, we used the 25-item National Eye Institute Visual Function Questionnaire (VFQ-25), which has been validated in patients with optic neuritis. ${ }^{12}$ The VFQ-25 consists of a set of 24 vision-targeted questions (and one general health question) generating a global score between $0 \%$ and $100 \%$ and 10 vision-related subscores.

Statistics. All statistics were performed by the STATISTICA software package (Statistica 9, Statsoft Inc., 1984-2010). Student $t$ tests were performed to compare different variables in the 2 groups of patients (MS vs OPT).

RESULTS Ophthalmologic evaluation. Mean far visual acuity measured in each eye was significantly higher in the OPT group $(0.33 \pm 0.21 \operatorname{logMAR}$, 20/40) than in the MS group $(0.55 \pm 0.28 \log$ MAR, $20 / 80)(\mathrm{t}[32]=2.5, p<0.05)$. Near visual acuity, obtained in 13 out of 14 patients in the OPT group and all patients in the MS group, did not differ significantly between the OPT $(0.41 \pm 0.21 \log$ MAR, $\mathrm{P} 3)$ and the MS groups $(0.51 \pm 0.29 \log \mathrm{MAR}, \mathrm{P} 4)$ $(\mathrm{t}[31]=1.7, p>0.05)$.

With the exception of one patient (OPT10), none of the patients in the OPT group had clinical signs of ocular or optic nerve dysfunction. In the MS group, 15 patients had chronic signs of bilateral optic neuropathy and one patient (MS17) of unilateral optic neuropathy. In the 4 remaining patients with MS without any sign of optic neuropathy, mean far visual acuity was $0.35 \pm 0.27 \log$ MAR (20/40).

Visual acuity was poor in both groups of patients, and far visual acuity was significantly more impaired in the patients with MS with signs of optic neuropathy than in the patients with OPT.

Eye movements. Figure 2 shows eye movement recordings from, respectively, one patient with OPT and one patient with MS, while figure 3 shows the results of eye movement recordings in the 2 patient groups. Table 1 gives the values of each eye movement parameter in individual patients.

Nystagmus was predominantly in the torsional and vertical planes in the OPT group and the torsional and horizontal planes in the MS group.

Mean amplitude and mean velocity were significantly higher in the OPT group $(8.00 \pm 7.02 \mathrm{deg}$, $16.00 \pm 13.71 \mathrm{deg} / \mathrm{s})$ compared with the MS group $(1.03 \pm 0.88 \mathrm{deg}, 6.35 \pm 5.05 \mathrm{deg} / \mathrm{s})$ (respectively $\mathrm{t}[32]=4.4, p<0.001, \mathrm{t}[32]=2.9, p<0.01)$ (figure 3, A and B). Furthermore, the amplitude of 


\section{Figure $1 \quad$ MRI data}
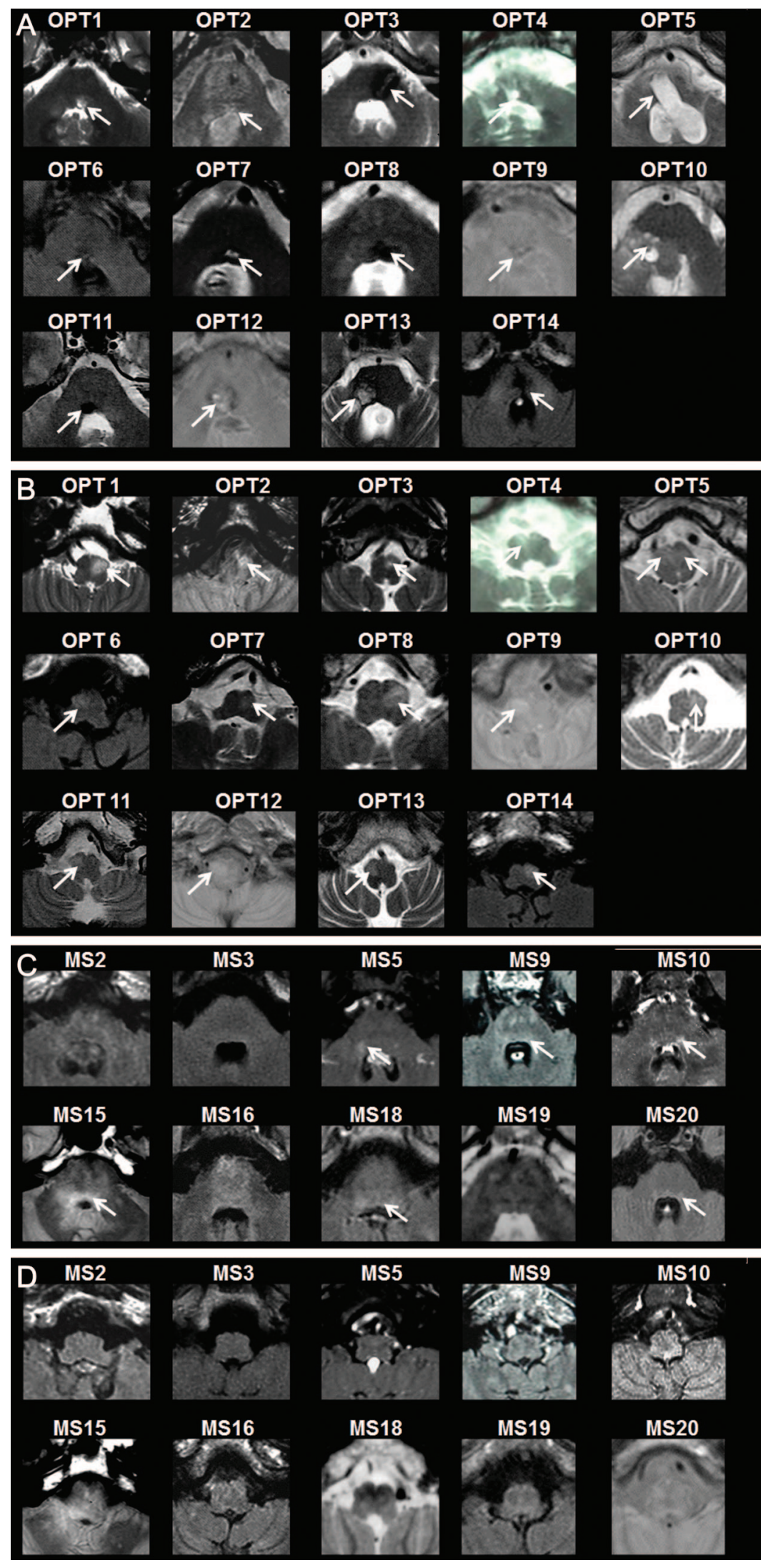

Axial fluid-attenuated inversion recovery or T2 MRI (1.5-T GE scanners) at midpontine tegmentum level ( $A$ and $C)$, inferior olive level $(B$ and $D)$, and in the patients with oculopalatal nystagmus was more variable in patients with OPT than patients with MS.

The fast Fourier transform showed a narrow frequency peak in the patients with MS that matched with the frequency obtained from manual measurements. However, in the patients with OPT, the peak was wide, less visible, and did not match with the manual measurement. As a consequence, frequency was measured manually for subsequent statistical analysis. The mean frequency was significantly lower in the OPT group $(1.76 \pm 0.72 \mathrm{~Hz})$ than the MS group $(4.65 \pm 0.59 \mathrm{~Hz})(\mathrm{t}[32]=12.9$, $p<0.001$ ) (figure 3C). The frequency in the OPT group never exceeded $3 \mathrm{~Hz}$ and in the MS group always exceeded $4 \mathrm{~Hz}$. Furthermore, for individual OPT patients the frequency of nystagmus was highly irregular (see figure 2).

The mean symmetry index of all 34 patients was $33.3 \% \pm 28.2 \%$. It was significantly higher in the OPT group $(44.6 \% \pm 28.7 \%)$ than the MS group $(25.4 \% \pm 25.6 \%)\left(\mathrm{t}[32]=2.05,{ }^{32} p<0.05\right)$ (figure 3D). Furthermore, while $13 / 14$ OPT patients had a symmetry index above $10 \%$, this was only the case in $13 / 20$ patients with MS.

The pendular nystagmus had a higher amplitude, velocity, and symmetry index and lower frequency in the OPT group than the MS group. Furthermore, the nystagmus in individual patients with OPT was more variable in amplitude and irregular in frequency.

VFQ-25. VFQ-25 answers were obtained from 12 of the 14 patients with OPT and 17 of the 20 patients with MS. The global score was lower $(30.39 \pm 9.09)$ in patients with OPT than patients with MS $(54.26 \pm 19.76)(\mathrm{t}[27]=3.9, p<0.001)$ (figure e-1). The subscores for pain, near, far, and peripheral vision, social life, mental state, and dependency on

tremor (OPT) (A and B) and patients with multiple sclerosis (MS) (C and D). White arrows indicate abnormal hypersignals. In all patients with OPT, we observed a unique focal lesion at the level of the pontine tegmentum (A). The lesion was right-sided in 5 patients, left-sided in 4 patients, and paramedian in 5 patients. When lateralized, the lesion was ipsilateral to T2 inferior olivary nucleus (ION) hypersignal. We observed a hypersignal at the level of the ION in all patients in the OPT group (B). The hypersignal was right-sided in 6 patients, left-sided in 7, and bilateral in 1 patient. Unilateral hypersignal was associated with asymmetric nystagmus in 8 cases out of 13, predominant in the contralateral eye in 7 out of 8 cases. The only case of bilateral hypersignal showed asymmetric nystagmus predominant on the left eye. In 6 out of 10 patients in the MS group, we observed multiple areas of patchy hypersignals at the level of the pontine tegmentum (C). These hypersignals likely corresponded to demyelinating lesions. None of the patients in the MS group presented ION hypersignal (D). 


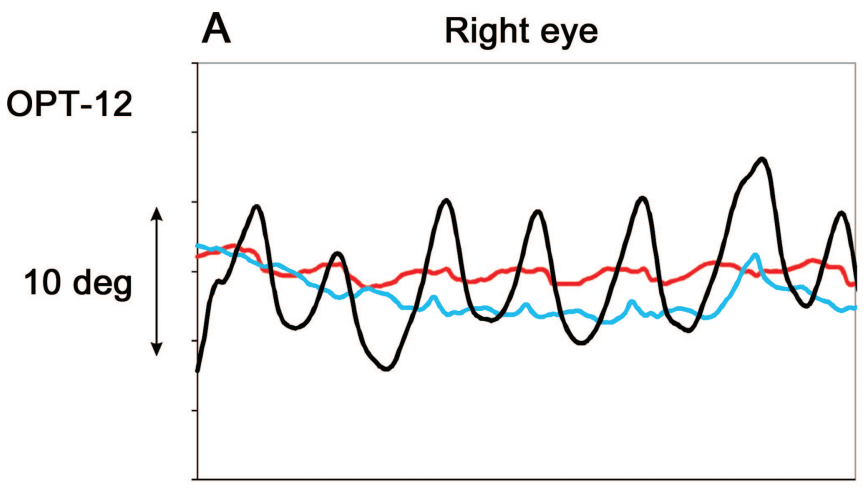

B Left eye

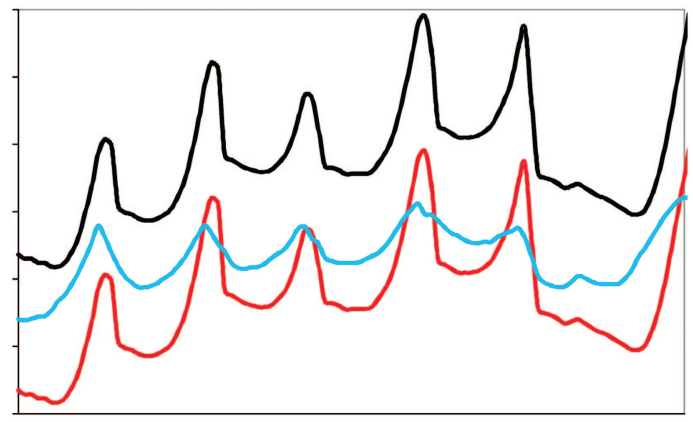

MS-15
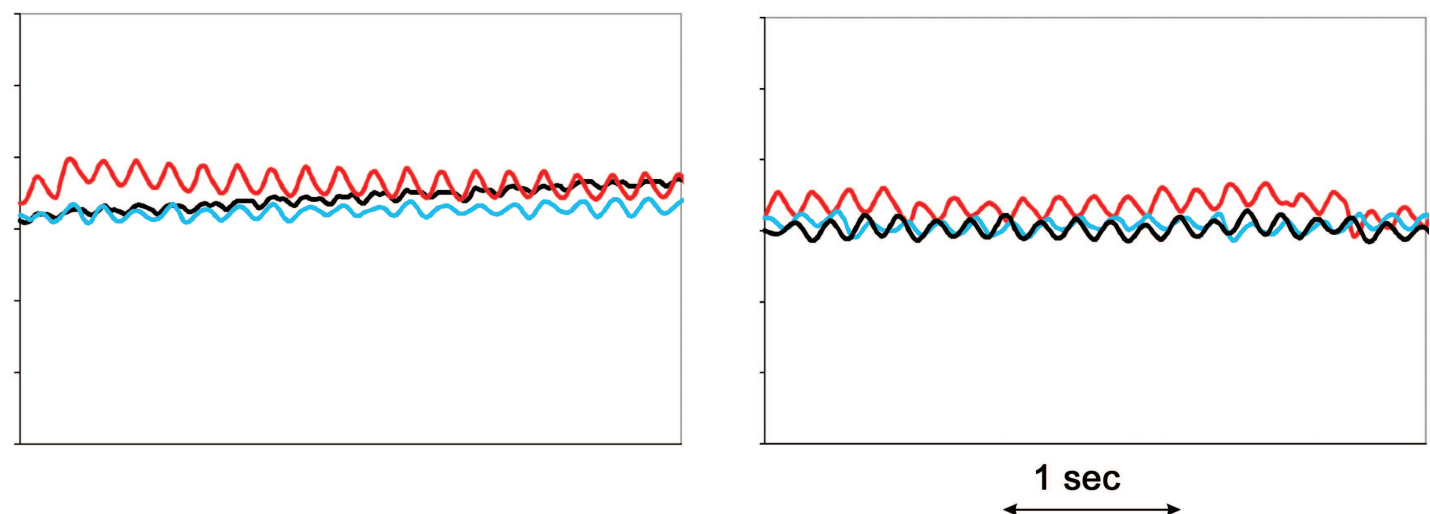

Eye position traces (in degrees) with time (in seconds) for right eye (A) and left eye (B) in one patient with OPT (upper panels) and one patient with MS (lower panels). Red line: horizontal position; black line: vertical position; blue line: torsional position.

others were all significantly lower in the patients with OPT than the patients with MS (all $p \leq 0.05$ ).

Correlations were performed on data from all 34 patients (both MS and OPT). We found no significant correlation between the global VFQ-25 score and mean amplitude $(r=0.26)$, peak velocity $(r=$ $0.26)$, or symmetry index $(r=0.03)$ of eye oscillations, nor between the global VFQ-25 score and far visual acuity $(r=0.03)$.

The vision-specific health-related quality of life was more deteriorated in the OPT group than the MS group. There was no correlation between the global score on the VFQ-25 scale and nystagmus characteristics, nor with visual acuity.

DISCUSSION This study shows clear differences in the features of nystagmus and in the functional consequences of APN in patients with OPT compared to patients with MS.

Here we demonstrate that APN in the context of OPT is of low frequency (maximum $3 \mathrm{~Hz}$ ) and high amplitude (up to $30 \mathrm{deg}$ ), while in MS it is of high frequency (minimum $4 \mathrm{~Hz}$ ) and low amplitude (maximum 3-4 deg). Some caution is needed in interpreting the results of our frequency analysis because of our low sampling rate. However, these data are consistent with previously published data in patients with MS reporting a nystagmus of 2-5 deg amplitude $^{13,14}$ and of $3.6 \mathrm{~Hz}$ mean frequency ${ }^{6,13-15}$ and in patients with OPT a nystagmus of 2-10 deg amplitude ${ }^{11,16}$ and of $1-3 \mathrm{~Hz}$ frequency. ${ }^{11,16,17}$ In addition, we found that the velocity of eye oscillations was higher in patients with OPT than patients with MS, but the cutoff point was not as clear as for frequency. In our study, the main direction of nystagmus was in the torsional and horizontal planes in the MS group and the vertical and torsional planes in the OPT group. This is consistent with previous recordings of 3-dimensional eye motion in APN. ${ }^{11,15,18,19}$ Even if the predominant horizontal plane in MS and vertical plane in OPT is a frequent observation, the direction of the nystagmus cannot strictly differentiate between the 2 etiologies. Previous studies that tested APN asymmetry in a subjective way found an equivalent percentage of patients with asymmetric APN (30\%-50\%) in both MS and OPT groups. ${ }^{1,11,13-15,18-21}$ In contrast, our eye movement data show that OPT is more frequently associated with asymmetric pendular nystagmus, and this feature may help distinguish patients with MS from patients with OPT. It should be noted that in those patients with MS with INO, impaired adduction 
A

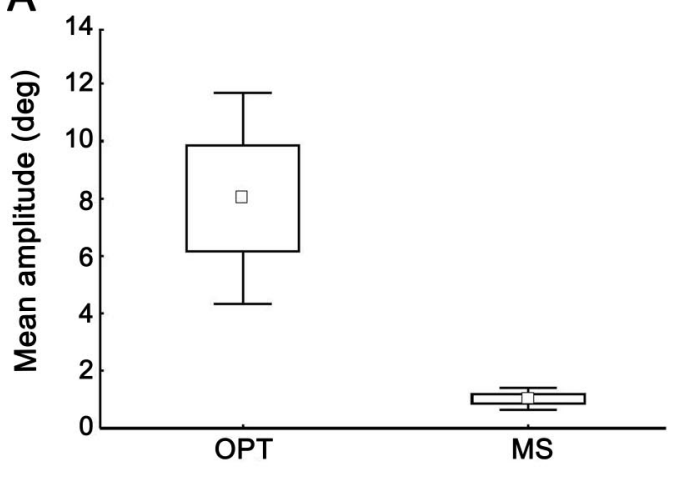

C

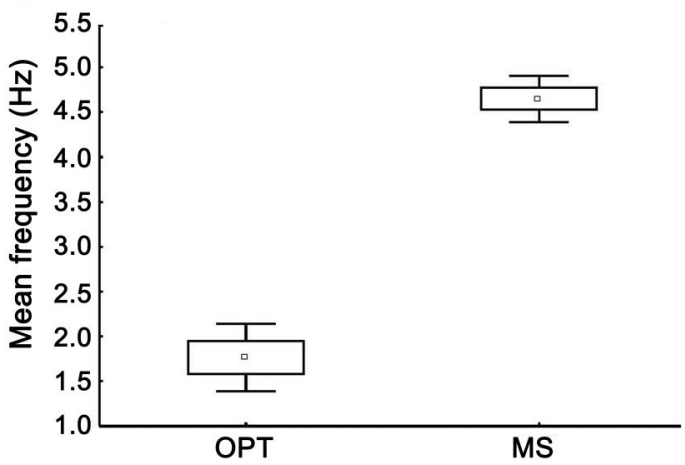

B

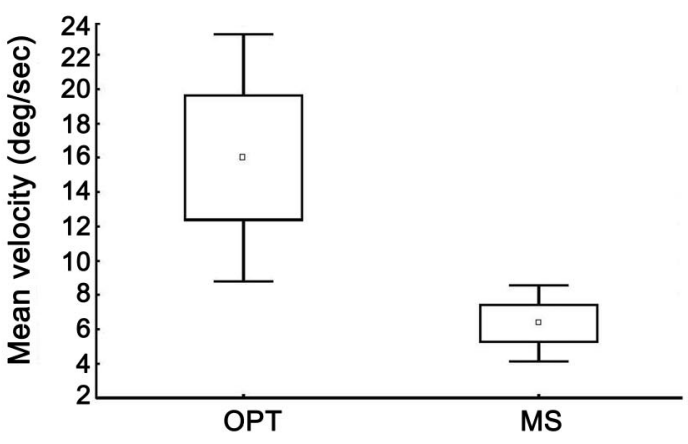

D

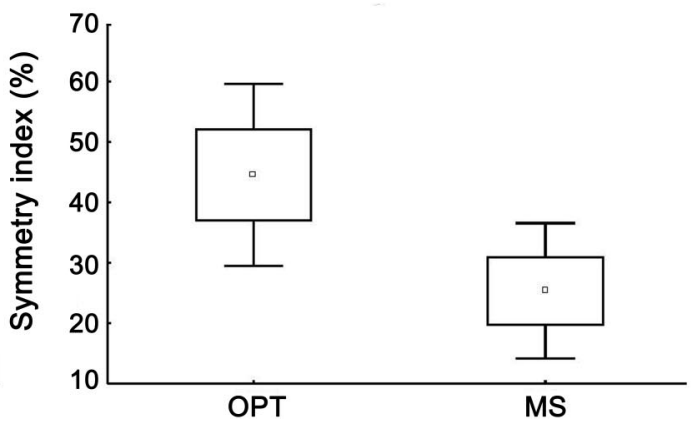

Mean amplitude (A), peak velocity (B), frequency (C), and symmetry index (D) of pendular nystagmus in the oculopalatal tremor (OPT) group (left side) and the multiple sclerosis (MS) group (right side). In each figure, the central squares represent the mean, the boxes the standard error, and the error bars the $95 \%$ confidence interval.

could influence the symmetry index. We found that the waveform and the frequency of the nystagmus in OPT was more variable and less sinusoidal than in patients with MS. While these observations have already been reported in patients with either APN due to $\mathrm{OPT}^{11,22}$ or $\mathrm{MS},{ }^{15,19}$ by comparing the 2 patient groups in the same study we show that this feature may be important for establishing a differential diagnosis between MS and OPT.

These data provide evidence of different underlying mechanisms in APN due to OPT or MS.

The most recent model of the mechanisms responsible for these oscillations in MS suggests abnormal delays in the oculomotor feedback loops due to central demyelination. This hypothesis is supported by the sinusoidal aspect of APN associated with MS, its frequency of around $4-5 \mathrm{~Hz}$ as well as its small amplitude. ${ }^{23}$ Abnormal feedback loops could involve the oculomotor neural integrator which normally guarantees stable gaze through mathematical integration of preoculomotor signals. ${ }^{19}$ This idea is mainly supported by the saccadic resetting of nystagmus and by the predominant location of lesions in the pontine tegmentum that could include cell groups of the paramedian tract involved in the oculomotor neural integrator feedback loops. ${ }^{15}$ Abnormal feedback could also arise from an impairment in visual feedback secondary to a demyelination of the optic nerve. ${ }^{15}$ An abnormal visual feedback is supported by the frequent association of APN and optic neuropathy ${ }^{20,24,25}$ and the observation of larger oscillations in the eye with the more severe optic neuropathy. ${ }^{20}$ However, this abnormal visual feedback hypothesis is challenged by the APN insensitivity to darkness or to experimental change of visual feedback delay. ${ }^{19}$

The more influential model of OPT suggests a dual mechanism involving inferior olivary hypertrophy and cerebellar plasticity. ${ }^{22,26}$ First, disruption of inhibitory cerebellar modulation of the ION leads to the development of somato-somatic gap junctions between neurons, generating periodic oscillations that are transmitted to the cerebellar cortex. The second mechanism would be a superimposed cerebellar "smoothing" of the output signal leading to smoother and less periodic eye movements. This model is supported by the irregular aspect of APN associated with OPT, its low frequency of around $1-3 \mathrm{~Hz}$, and its asymmetry. ${ }^{5}$

The ambiguity of combining MS and OPT in the etiologies of APN is reinforced by the publications of 
Table 1 Dominant plane (DP), amplitude (A), velocity (V), frequency, and symmetrical index (SI) of acquired pendular nystagmus in oculopalatal (OPT) and multiple sclerosis (MS) groups ${ }^{a}$

\begin{tabular}{|c|c|c|c|c|c|c|c|c|c|}
\hline \multirow[b]{3}{*}{ Group } & \multirow[b]{3}{*}{ Patient } & \multicolumn{6}{|c|}{ Nystagmus } & \multirow[b]{3}{*}{ Frequency, c/s } & \multirow[b]{3}{*}{$\mathrm{SI}, \%$} \\
\hline & & \multicolumn{3}{|l|}{ RE } & \multicolumn{3}{|l|}{ LE } & & \\
\hline & & DP & $A$, deg & $V, \operatorname{deg} / \mathrm{s}$ & DP & A, deg & $V, \operatorname{deg} / \mathrm{s}$ & & \\
\hline \multirow[t]{14}{*}{ OPT } & 1 & $\mathrm{~T}$ & 12 & 20 & $\mathrm{~V}$ & 4 & 8 & 1 & 50 \\
\hline & 2 & $\mathrm{VT}$ & 5 & 15 & VT & 8 & 15 & 1 & 23 \\
\hline & 3 & V & 10 & 10 & & 0 & 0 & 0.7 & 100 \\
\hline & 4 & $\mathrm{~T}$ & 6 & 10 & $\mathrm{~T}$ & 5 & 10 & 1.65 & 9 \\
\hline & 5 & V & 2 & 5 & V & 4 & 10 & 2.5 & 33 \\
\hline & 6 & & 0 & 0 & VT & 2 & 5 & 1.15 & 100 \\
\hline & 7 & $\mathrm{~T}$ & 7 & 11 & HVT & 2 & 4 & 0.9 & 56 \\
\hline & 8 & V & 3 & 10 & V & 2 & 10 & 2.5 & 11 \\
\hline & 9 & $\mathrm{~T}$ & 3 & 10 & $\mathrm{H}$ & 4 & 10 & 2.5 & 33 \\
\hline & 10 & VT & 3 & 7 & $\mathrm{~T}$ & 10 & 16 & 2.4 & 54 \\
\hline & 11 & V & 3 & 10 & V & 2 & 10 & 1.95 & 20 \\
\hline & 12 & $\mathrm{~T}$ & 12 & 28 & $T$ & 30 & 60 & 1.35 & 60 \\
\hline & 13 & $\mathrm{~T}$ & 2 & 4 & V & 3 & 6 & 1.65 & 50 \\
\hline & 14 & $\mathrm{~T}$ & 8 & 17 & $\mathrm{~T}$ & 5 & 12 & 1.3 & 25 \\
\hline \multirow[t]{20}{*}{ MS } & 1 & $\mathrm{HT}$ & 1.5 & 10 & $\mathrm{H}$ & 1.5 & 10 & 5 & 20 \\
\hline & 2 & $T$ & 1 & 5 & $\mathrm{H}$ & 0.5 & 5 & 5 & 33 \\
\hline & 3 & $\mathrm{H}$ & 1 & 8 & $\mathrm{H}$ & 1 & 6 & 4 & 0 \\
\hline & 4 & $T$ & 1 & 6 & $\mathrm{HV}$ & 0.5 & 5 & 5 & 33 \\
\hline & 5 & $\mathrm{H}$ & 1.5 & 8 & $\mathrm{H}$ & 2 & 16 & 5 & 14 \\
\hline & 6 & $\mathrm{H}$ & 0.5 & 3 & $\mathrm{H}$ & 0.5 & 3 & 5 & 0 \\
\hline & 7 & $T$ & 4 & 20 & $T$ & 2 & 18 & 4 & 33 \\
\hline & 8 & $\mathrm{~T}$ & 0.3 & 2 & $T$ & 0.3 & 2 & 5 & 9 \\
\hline & 9 & $\mathrm{H}$ & 1.5 & 10 & $\mathrm{H}$ & 2 & 10 & 5 & 14 \\
\hline & 10 & $T$ & 0.5 & 5 & & 0 & 0 & 4 & 100 \\
\hline & 11 & $\mathrm{HV}$ & 0.25 & 2 & $\mathrm{HT}$ & 0.3 & 2 & 5 & 9 \\
\hline & 12 & $\mathrm{H}$ & 1 & 7 & $T$ & 0.5 & 4 & 6 & 33 \\
\hline & 13 & VT & 0.5 & 4 & $\mathrm{VT}$ & 0.5 & 4 & 4 & 0 \\
\hline & 14 & $\mathrm{H}$ & 0.25 & 3 & $\mathrm{~T}$ & 0.5 & 5 & 5 & 33 \\
\hline & 15 & $T$ & 0.5 & 2 & $\mathrm{~T}$ & 0.5 & 2 & 5 & 0 \\
\hline & 16 & $T$ & 0.5 & 2.5 & $T$ & 0.5 & 3 & 4 & 0 \\
\hline & 17 & $T$ & 0.3 & 1 & $T$ & 0.5 & 2 & 5 & 33 \\
\hline & 18 & $\mathrm{H}$ & 1 & 4 & VT & 0.5 & 2 & 4 & 33 \\
\hline & 19 & T & 0.5 & 2 & $\mathrm{~T}$ & 1 & 3 & 4 & 33 \\
\hline & 20 & $\mathrm{~V}$ & 2 & 13 & $\mathrm{~T}$ & 0.3 & 3 & 4 & 74 \\
\hline
\end{tabular}

Abbreviations: $\mathrm{c}=$ cycle; $\mathrm{H}$ = horizontal; $\mathrm{T}=$ torsional; $\mathrm{V}=$ vertical.

a In the OPT group, the dominant plane of nystagmus was torsional in 11 eyes, vertical in 9 eyes, mixed vertico-torsional in 4 eyes, horizonto-vertico-torsional in 1 eye, horizontal in 1 eye, and absent in 2 eyes ( 2 different patients). The dominant plane of eye movement in the MS group was torsional in 18 eyes, horizontal in 13 eyes, mixed vertico-torsional in 3 eyes, mixed horizonto-torsional in 2 eyes, mixed horizonto-vertical in 2 eyes, vertical in 1 eye, and absent in 1 eye.

observations of OPT in MS. Indeed, old articles suggest some rare cases of OPT or palatal tremor secondary to MS. ${ }^{16,27,28}$ The features of nystagmus, its frequency and association with palatal tremor, suggested OPT. However, most of the time, the diagnosis of MS was only based on the young age of the patient. Critical reading of these publications suggests that some cases could correspond to brainstem hemorrhage or even essential palatal tremor. A notable exception is the report of a patient with clinical, biological, and MRI criteria for MS, developing OPT associated with ION hypersignal on MRI. ${ }^{29}$ 
The nystagmus had a pendular aspect, 3-4 deg amplitude, $2 \mathrm{~Hz}$ frequency, and was in the horizontal and vertical planes. Therefore, OPT might exceptionally develop after an inflammatory focal lesion due to MS. In this case, the nystagmus may present the features of ocular tremor associated with OPT instead of the high-frequency, low-amplitude pendular nystagmus usually observed in MS.

Visual acuity was poor in both groups of patients, and far visual acuity was significantly more impaired in the patients with MS than the patients with OPT. Patients with MS had associated signs of optic neuropathy in 15 out of 20 cases, which could explain the differences in terms of visual acuity. Conversely, vision-specific health-related quality of life was more deteriorated in the OPT group than the MS group. In our study, correlation analyses suggested that the visual functional score was not related to visual acuity, amplitude, velocity, or frequency of APN. Interestingly, a recent study comparing patients with pontine hemorrhage showed that global functional scores were more severe in patients with ION hypersignal, even though motor paresis, sensory disturbance, and ataxia were comparable, ${ }^{30}$ but they did not attempt to correlate functional scores with eye movement impairments. One explanation for the lower scores on the vision-specific quality of life scale in the OPT group could be the fact that the deficit in horizontal eye movements is more profound in patients with OPT than in patients with MS. Another explanation could be that APN in MS develops slowly whereas it develops rapidly in patients with OPT. Finally, patients with MS show progressive cognitive impairment in which anosognosia might lead to them ignoring part of the visual functional consequences of the disease. We suggest that the visual functional consequences of APN should be taken into consideration in future therapeutic trials.

In the first double-blind, controlled study performed in 15 patients with APN, 9 were patients with MS and 3 had stroke suggesting the presence of OPT. ${ }^{6}$ Gabapentin was efficient in the treatment of APN but the published data do not allow a comparison of the results in patients on the basis of different underlying etiologies. In a second trial showing that gabapentin was more successful than vigabatrin in improving APN, only patients with MS were tested. ${ }^{31}$ In contrast to the results of a recent study in a small group of patients, ${ }^{10}$ Shery et $\mathrm{al}^{8}$ found that gabapentin and memantine were both effective in treating APN secondary to MS but not to other neurologic diseases, which is in accordance with our personal clinical experience. Finally, the studies from Starck ${ }^{21,32}$ showing improvement of APN with gabapentin and memantine only tested patients with MS.
On the basis of this literature and our personal clinical experience, gabapentin and memantine appear to be effective in APN associated with MS but not OPT. Based on the dual-model hypothesis of OPT (see above), it was recently proposed that treatments should combine drugs acting on cerebellar modulation (clonazepam, alprazolam, primidone, topiramate, memantine) and drugs reducing the electrotonic coupling between the hypertrophied inferior olive neurons by blocking connections (quinine, carbenoxolone, mefloquine). ${ }^{22,26}$ To date, none of these combinations of drugs have been tested in patients with APN arising from OPT.

The results of this study emphasize the different clinical aspects of these 2 etiologies of APN, the fact that the functional consequences of $\mathrm{APN}$ are more severe in patients with OPT, and the need to differentiate both etiologies in future textbooks, reviews, and pharmacologic trials.

\section{AUTHOR CONTRIBUTIONS}

Statistical analysis was conducted by Dr. Caroline Tilikete.

\section{ACKNOWLEDGMENT}

The authors thank Dr. Karen Reilly for English review.

\section{DISCLOSURE}

Dr. Tilikete serves on the editorial boards of Journal of Neuro-Ophthalmology and Frontiers in Neuro-Ophthalmology and receives research support from Programme Hospitalier de Recherche Clinique and Fondation de l'Avenir, France. L. Jasse and Dr. Pelisson report no disclosures. Dr. Vukusic serves on scientific advisory boards for Biogen Idec, Merck Serono, Novartis, sanofiaventis, and Teva Pharmaceutical Industries Ltd.; has received funding for travel from Biogen Idec and Merck Serono; serves as a consultant for Merck Serono, sanofi-aventis, Teva Pharmaceutical Industries Ltd., and Biogen Idec; and receives research support from Bayer Schering Pharma, Biogen Idec, Merck Serono, Novartis, sanofi-aventis and Teva Pharmaceutical Industries Ltd. Dr. Durand-Dubief has received funding for travel from Biogen Idec, Bayer Schering Pharma, Merck Serono, sanofi-aventis, Novartis, and Teva Pharmaceutical Industries Ltd. C. Urquizar and Dr. Vighetto report no disclosures.

Received July 24, 2010. Accepted in final form December 22, 2010.

\section{REFERENCES}

1. Deuschl G, Toro C, Valls-Sole J, Zeffiro T, Zee DS, Hallett M. Symptomatic and essential palatal tremor: 1 : clinical, physiological and MRI analysis. Brain 1994; 117:775-788.

2. Guillain G, Mollaret P. Deux cas de myoclonies synchrones et rythmées vélo-pharyngo-oculo-diaphragmatiques: le problème anatomique et physio-pathologique de ce syndrome. Rev Neurol 1931;2:545-566.

3. Nakada T, Kwee IL. Oculopalatal myoclonus. Brain 1986; 109:431-441.

4. Tilikete C, Hannoun S, Nighoghossian N, SappeyMarinier D. Oculopalatal tremor and severe late-onset cerebellar ataxia. Neurology 2008;71:301.

5. Leigh RJ, Zee DS. The Neurology of Eye Movements, 4th ed. Oxford: Oxford University Press; 2006.

6. Averbuch-Heller L, Tusa RJ, Fuhry L, et al. A doubleblind controlled study of gabapentin and baclofen as 
treatment for acquired nystagmus. Ann Neurol 1997; 41:818-825.

7. Rucker JC. An update on acquired nystagmus. Semin Ophthalmol 2008;23:91-97.

8. Shery T, Proudlock FA, Sarvananthan N, McLean RJ, Gottlob I. The effects of gabapentin and memantine in acquired and congenital nystagmus: a retrospective study. Br J Ophthalmol 2006;90:839-843.

9. Straube A, Leigh RJ, Bronstein A, et al. EFNS task forcetherapy of nystagmus and oscillopsia. Eur J Neurol 2004; 11:83-89.

10. Thurtell MJ, Joshi AC, Leone AC, et al. Crossover trial of gabapentin and memantine as treatment for acquired nystagmus. Ann Neurol 2010;67:676-680.

11. Kim JS, Moon SY, Choi KD, Kim JH, Sharpe JA. Patterns of ocular oscillation in oculopalatal tremor: imaging correlations. Neurology 2007;68:1128-1135.

12. Ma SL, Shea JA, Galetta SL, et al. Self-reported visual dysfunction in multiple sclerosis: new data from the VFQ-25 and development of an MS-specific vision questionnaire. Am J Ophthalmol 2002;133:686-692.

13. Gresty MA, Ell JJ, Findley LJ. Acquired pendular nystagmus: its characteristics, localising value and pathophysiology. J Neurol Neurosurg Psychiatry 1982;45:431-439.

14. Lopez LI, Bronstein AM, Gresty MA, Du Boulay EP, Rudge P. Clinical and MRI correlates in 27 patients with acquired pendular nystagmus. Brain 1996;119:465-472.

15. Averbuch-Heller L, Zivotofsky AZ, Das VE, DiScenna $\mathrm{AO}$, Leigh RJ. Investigations of the pathogenesis of acquired pendular nystagmus. Brain 1995;118:369-378.

16. Chokroverty S, Barron KD. Palatal myoclonus and rhythmic ocular movements: a polygraphic study. Neurology 1969;19:975-982.

17. Talks SJ, Elston JS. Oculopalatal myoclonus: eye movement studies, MRI findings and the difficulty of treatment. Eye 1997;11:19-24.

18. Averbuch-Heller L, Zivotofsky AZ, Remler BF, Das VE, Dell'Osso LF, Leigh RJ. Convergent-divergent pendular nystagmus: possible role of the vergence system. Neurology 1995;45:509-515.

19. Das VE, Oruganti P, Kramer PD, Leigh RJ. Experimental tests of a neural-network model for ocular oscillations caused by disease of central myelin. Exp Brain Res 2000; 133:189-197.
20. Barton JJ, Cox TA. Acquired pendular nystagmus in multiple sclerosis: clinical observations and the role of optic neuropathy. J Neurol Neurosurg Psychiatry 1993;56:262267.

21. Starck M, Albrecht H, Pollmann W, Dieterich M, Straube A. Acquired pendular nystagmus in multiple sclerosis: an examiner-blind cross-over treatment study of memantine and gabapentin. J Neurol 2010;257:322-327.

22. Shaikh AG, Hong S, Liao K, et al. Oculopalatal tremor explained by a model of inferior olivary hypertrophy and cerebellar plasticity. Brain 2010;133:923-940.

23. Leigh RJ. Clinical features and pathogenesis of acquired forms of nystagmus. Baillieres Clin Neurol 1992;1:393416.

24. Larmande P, Cassarini JF, Maillot F. [Monocular circumduction nystagmus: are the central oculomotor pathways partly monocular?] Rev Neurol 1995;151:338-340.

25. Barton JJ, Cox TA, Digre KB. Acquired convergenceevoked pendular nystagmus in multiple sclerosis. J Neuroophthalmol 1999;19:34-38.

26. Hong S, Leigh RJ, Zee DS, Optican LM. Inferior olive hypertrophy and cerebellar learning are both needed to explain ocular oscillations in oculopalatal tremor. Prog Brain Res 2008;171:219-226.

27. Dereux MJ. Myoclonies vélo-pharyngo-laryngées et oculaire chez un malade atteint de sclérose en plaques. Rev Neurol 1938;69:135-138.

28. Krebs ME, Puech P, Lemoine J. Un cas de myoclonies oculo-vélo-palato-laryngées. Rev Neurol 1932;5:955-963.

29. Revol A, Vighetto A, Confavreux C, Trillet M, Aimard G. [Oculo-palatal myoclonus and multiple sclerosis.] Rev Neurol 1990;146:518-521.

30. Yagura H, Miyai I, Hatakenaka M, Yanagihara T. Inferior olivary hypertrophy is associated with a lower functional state after pontine hemorrhage. Cerebrovasc Dis 2007;24: 369-374.

31. Bandini F, Castello E, Mazzella L, Mancardi GL, Solaro C. Gabapentin but not vigabatrin is effective in the treatment of acquired nystagmus in multiple sclerosis: how valid is the GABAergic hypothesis? J Neurol Neurosurg Psychiatry 2001;71:107-110.

32. Starck M, Albrecht H, Pollmann W, Straube A, Dieterich $\mathrm{M}$. Drug therapy for acquired pendular nystagmus in multiple sclerosis. J Neurol 1997;244:9-16.

\section{Neurology ${ }^{\circledR}$ Launches Subspecialty Alerts by E-mail!}

Customize your online journal experience by signing up for e-mail alerts related to your subspecialty or area of interest. Access this free service by visiting http://www.neurology.org/cgi/alerts/ etoc.xhtml or click on the "E-mail Alerts" link on the home page. An extensive list of subspecialties, methods, and study design choices will be available for you to choose from-allowing you priority alerts to cutting-edge research in your field! 